\title{
Metacognitive Awareness of Undergraduate Students in Relation to their Academic Achievement
}

\author{
Dr. Neena Sawhney ${ }^{1 *}$, Dr. Sneh Bansal ${ }^{2}$
}

\section{ABSTRACT}

Metacognition is an individual's knowledge of their own cognitive processes and their ability to control these processes by organizing, monitoring and modifying them as a function of learning. Students who succeed academically often rely on being able to think effectively and independently in order to take charge of their learning. These students have mastered fundamental but crucial skills such as keeping their workspace organized, completing tasks on schedule, making a plan for learning, monitoring their learning path, and recognizing when it might be useful to change course. Learning cognitive and metacognitive strategies offers students the tools to "drive their brains." Being metacognitive can be likened to being more conscious, reflective, and aware of one's progress along the learning path. The present study was undertaken to find out the relationship between metacognitive awareness and academic achievement of undergraduate students. The sample of the study comprised of 100 undergraduate students from various colleges of Chandigarh. Metacognitive Awareness Inventory (MAI) by Schraw \& Dennison (1994) was used to measure the metacognitive awareness. The findings revealed a significant difference in academic achievement of undergraduate students with high and low scores in metacognitive awareness.

Keywords: Metacognition, Metacognitive awareness, Knowledge about Cognition, Regulation of Cognition, Academic achievement.

Metacognition can simply be explained by "thinking about thinking”. A more appropriate explanation is that metacognition is the awareness or understanding of one's acquired knowledge. This understanding can be expressed through actual use of this knowledge, or by the ability to verbally describe it. In other words, it is about being aware of your own thinking and what possibilities you see when solving problems, making decisions or interpret a text. It also means making intentional strategy-choices when facing problems, verifying the direction towards which you are heading and continuously supervising your course of action. It is about having an active, conscious and systematic attitude and being able to reflect upon your own learning.

\footnotetext{
${ }^{1}$ Principal, Chandigarh College of Education, Landran, Mohali

${ }^{2}$ Assistant Professor, Chandigarh College of Education, Landran, Mohali

*Corresponding Author

(C) 2015 I N Sawhney, S Bansal; licensee IJIP. This is an Open Access Research distributed under the terms of the Creative Commons Attribution License (http://creativecommons.org/licenses/by/2.0), which permits unrestricted use, distribution, and reproduction in any Medium, provided the original work is properly cited.
} 
Metacognition is important in learning and is a strong predictor of academic success (Dunning, Johnson, Ehrlinger and Kruger, 2003; Kruger and Dunning, 1999). Students with good metacognition demonstrate good academic performance compared to students with poor metacognition. Students with poor metacognition may benefit from metacognitive training to improve their metacognition and academic performance. Individual differences exist in metacognition and people with poor metacognition are deemed "incompetent" as they perform inadequately relative to their peers (Kruger and Dunning, 1999). Metacognition enables students to be strategic in their learning by, for instance, learning new information rather than focusing on studying information already learned (Everson and Tobias, 1998). Numerous studies have examined the metacognitive awareness of students at various levels.

Narang,D. and Saini, S. (2013) studied the impact of metacognition on academic performance of rural adolescents (13-16 years). The study was carried out in rural schools of block-I, Ludhiana District. The sample comprised of 240 rural adolescents equally distributed over four grades (7th, 8th, 9th and 10th grade), two sexes and two socio-economic groups i.e. middle and low socio-economic group. Metacognitive skills of the subjects were assessed using a self-structured Questionnaire adapted from Metacognition Inventory and Metacognitive Awareness Inventory. To assess the academic performance of the subjects, the aggregate percentage of marks obtained by them in the last school examination was procured from the concerned teachers. Results revealed that the major proportion of subjects with high level of metacognition also performed above average in academics. Further, analysis depicted that both the components of metacognition viz. 'Knowledge of Cognition' and 'Regulation of Cognition' significantly contributed towards the academic performance of the adolescents.

McCabe J. (2011) undertook two studies which examined undergraduates' metacognitive awareness of six empirically-supported learning strategies. Study 1 results overall suggested an inability to predict the learning outcomes of educational scenarios describing the strategies of dual-coding, static-media presentations, low-interest extraneous details, testing, and spacing; there was, however, weak endorsement of the strategy of generating one's own study materials. In addition, an independent measure of metacognitive self-regulation was correlated with scenario performance. Study 2 demonstrated higher prediction accuracy for students who had received targeted instruction on applied memory topics in their psychology courses, and the best performance for those students directly exposed to the original empirical studies from which the scenarios were derived. In sum, this research suggests that undergraduates are largely unaware of several specific strategies that could benefit memory for course information; further, training in applied learning and memory topics has the potential to improve metacognitive judgments in these domains.

Karpicke . JD., Butler AC., \& Roediger, HL. (2009) investigated students' real-world study behaviours and surveyed 177 college students and asked them (1) to list strategies they used when studying (an open-ended free report question) and (2) to choose whether they would reread 
or practise recall after studying a textbook chapter (a forced report question). The results of both questions point to the same conclusion: A majority of students repeatedly read their notes or textbook (despite the limited benefits of this strategy), but relatively few engage in self-testing or retrieval practise while studying. They suggested that many students experience illusions of competence while studying and that these illusions have significant consequences for the strategies students select when they monitor and regulate their own learning.

Coutinho , Savia A. (2007) examined the relationship between mastery goals, performance goals, metacognition, and academic success. Regression analyses revealed a partial mediation effect in the relationship between mastery goals and academic performance. Performance goals were unrelated to academic performance. This study supports research findings suggesting that students with mastery goals reap the rewards of academic success.

Sperling et al (2004) utilizing the MAI to determine college student metacognitive awareness, found a significant correlation between the knowledge of cognition factor and the regulation of cognition factor. They also were interested in whether the MAI would be correlated with other measures of academic achievement such as SAT scores and high school average. They found no relation between scores on the MAI and measures of academic achievement. They were surprised to find a negative correlation between SAT math scores and the MAI scores.

Kelemen WL, Frost PJ, Weaver CA. (2000) highlighted that Individual differences in metacognitive accuracy are generally thought to reflect differences in metacognitive ability. If so, memory monitoring performance should be consistent across different meta-cognitive tasks and show high test-retest reliability. Two experiments examined these possibilities, using four common metacognitive tasks: ease of learning judgments, feeling of knowing judgments, judgments of learning, and text comprehension monitoring. Alternate-forms correlations were computed for metacognitive accuracy (with a 1-week interval between tests). Although individual differences in memory and confidence were stable across both sessions and tasks, differences in metacognitive accuracy were not. These results pose considerable practical and theoretical challenges for metacognitive researchers.

Overall, the findings in the research reviewed above regarding the correlation of metacognition with academic and achievement measures indicate that there exist a significant positive relationship between student's academic performance and metacognitive awareness. The present study examined the relationship between metacognitive awareness and academic achievement and is based on the hypothesis that the academic achievement is fully mediated by metacognition. This area of research was selected because it has not been investigated before and so contributes to the existing wealth of knowledge on achievement goals and metacognition in relation to academic success. Achievement goals are typically assessed using a sample of students in elementary and secondary schools and not students in universities. Therefore, another reason for this investigation was to contribute to existing educational psychology research on 
university students and allows for comparisons between elementary and secondary students and university students. The variables included were knowledge of cognition and regulation of cognition. Academic Performance was taken as dependent variable.

\section{OBJECTIVES}

1. To study gender differences in academic achievement among undergraduate students.

2. To study gender differences in metacognitive awareness among undergraduate students.

3. To study the academic achievement by undergraduate students having high or low level of metacognitive awareness

\section{Hypotheses}

1. There is no significant difference in academic achievement among undergraduate students in relation to gender.

2. There is no significant difference in metacognitive awareness among secondary school students in relation to gender.

3. There is no significant difference in academic achievement among undergraduate students having high or low level of Metacognitive awareness.

\section{Design and Sample of the study}

The study was conducted through descriptive survey method of research. The descriptive survey method has undoubtedly been the most popular and most widely used research method in education. This method requires sample for the conduct of the study with certain research tools for the conduct of the study. In every research project, it is not only difficult but also impossible to include the whole population. Therefore every research resorts to sampling. Generally what the research worker does is to select a part of whole population to draw conclusions and make generalizations about the whole based on the study of the representative part of whole of the population. The population of present study was school students studying in graduation (Ist year) from different colleges of Chandigarh (U.T.). In the present study, sample of 100 students, both boys and girls, was collected through random sampling technique from different colleges Chandigarh. Out of 100 students, total 91 students completely filled the inventory used for the study

\section{Tools Used}

1. Metacognitive Awareness Inventory (MAI) by Schraw \& Dennison ( 1994)

2. Academic achievement of the students was taken from their previous class results.

The Metacognitive Awareness Inventory (MAI) consists of 52-items which measure an individual's knowledge of cognition and regulation of cognition (Schraw \& Dennison, 1994). Within these two constructs, the MAI also examines individuals' monitoring, evaluation of learning, debugging strategies, conditional knowledge, planning, declarative knowledge, information management strategies, and procedural knowledge.

The Knowledge about Cognition dimension covers the areas of declarative, procedural and conditional knowledge as described below:

i. Declarative Knowledge i.e. The factual knowledge the learner needs before being able to process or use critical thinking related to the topic; Knowing about, what, or that; 
Knowledge of one's skills, intellectual resources, and abilities as a learner and that students can obtain knowledge through presentations, demonstrations, discussions.

ii. Procedural Knowledge i.e. The application of knowledge for the purposes of completing a procedure or process; Knowledge about how to implement learning procedures (e.g. strategies); Requires students know the process as well as when to apply process in various situations and that students can obtain knowledge through discovery, cooperative learning, and problem solving

iii. Conditional Knowledge i.e. The determination under what circumstances specific processes or skills should transfer; Knowledge about when and why to use learning procedures; Application of declarative and procedural knowledge with certain conditions presented and students can obtain knowledge through simulation.

The Regulation of Cognition dimension examines the individuals planning, information management strategies, comprehension monitoring, debugging strategies and evaluation as described below:

i. Planning i.e. goal setting, and allocating resources prior to learning

ii. Information Management Strategies i.e. Skills and strategy sequences used to process information more efficiently (e.g., organizing, elaborating, summarizing, selective focusing)

iii. Comprehension Monitoring i.e assessment of one's learning or strategy use

iv. Debugging Strategies i.e. strategies used to correct comprehension and performance errors

v. Evaluation i.e. analysis of performance and strategy effectiveness after a learning episode

\section{Reliability}

The internal consistency for the instrument was found to be $\alpha=.95$ (Schraw \& Dennison, 1994).

Validity

Schraw and Dennison (1994) found evidence for the MAI's structural validity through confirmatory factor analysis, in which a 2 -factor solution explained $65 \%$ of the variance in one sample, and $58 \%$ of the variance in another.

\section{Delimitations of Study}

1. The study was restricted to the undergraduate students of Chandigarh.

2. The sample consisted of undergraduate students (B.A/B.Com Ist Year).

3. The sample consisted of both boys and girl undergraduate students.

\section{Statistical Techniques Used}

The data obtained was subjected to statistical analysis and following statistical tools were used:

1. Descriptive analysis as mean, median and standard deviations were used wherever required.

2. Independent $t$ test were used to find the differences. 


\section{RESULTS AND DISCUSSION}

Table 1: Mean differential in the academic achievement of male and female undergraduate

\begin{tabular}{|l|l|l|l|l|l|l|}
\hline \multirow{2}{*}{ Variable } & \multicolumn{2}{|l|}{ Female (N= 33 ) } & \multicolumn{2}{l|}{ Male (N= 58) } & t-value & $\begin{array}{l}\text { Level of } \\
\text { Significance }\end{array}$ \\
\cline { 2 - 5 } & Mean & S.D. & Mean & S.D. & & .01 \\
\hline $\begin{array}{l}\text { Academic } \\
\text { Achievement }\end{array}$ & 72.1818 & 8.42413 & 65.0862 & 8.04872 & 3.975 & \\
\hline
\end{tabular}

The results entered in table 1 clearly indicate significant difference $(t=3.975)$ in academic achievement of undergraduate male and female students. Further, higher mean scores of female $(\mathrm{M}=72.1818)$ indicates that academic achievement of girls was significantly higher than the male students $(\mathrm{M}=65.0862)$

Table 2: Mean differentials in the knowledge about cognition, Regulation of cognition and total metacognitive awareness of undergraduate male and female students

\begin{tabular}{|l|l|l|l|l|l|l|}
\hline Dimensions of & \multicolumn{2}{l}{ Female(N= 33 ) } & \multicolumn{2}{l|}{ Male (N= 58) } & t-value & $\begin{array}{l}\text { Level } \\
\text { Significance }\end{array}$ \\
\cline { 2 - 7 } Metacognitive awareness & Mean & S.D. & Mean & S.D. & & of \\
\hline Knowledge about cognition & 12.70 & 3.644 & 11.63 & 3.120 & 1.467 & NS \\
\hline Regulation of cognition & 25.88 & 6.294 & 24.30 & 5.368 & 1.263 & NS \\
\hline $\begin{array}{l}\text { Total of both dimensions } \\
\text { Metacognitive awareness }\end{array}$ & 36.79 & 9.276 & 36.33 & 9.554 & .223 & NS \\
\hline
\end{tabular}

From the results in table 2, it is clear that there was no significant difference in knowledge about Cognition, Regulation of Cognition and total Metacognitive awareness. The results show that there is no gender difference in the knowledge about Cognition, Regulation of Cognition and total Metacognitive awareness. Girls and Boys are equally aware of their own Metacognitive processes.

Table 3: Mean differentials in the academic achievement of undergraduate students with high and low scores in total dimensions of metacognitive awareness

\begin{tabular}{|l|l|l|l|l|l|l|}
\hline \multirow{2}{*}{ Metacognitive awareness } & \multicolumn{2}{l|l}{ High score (n=24) } & \multicolumn{2}{l|}{ Low score (n=24) } & \multirow{2}{*}{ t-value } & $\begin{array}{l}\text { Level } \\
\text { Significance }\end{array}$ \\
\cline { 2 - 7 } & Mean & S.D. & Mean & S.D. & & .01 \\
\hline $\begin{array}{l}\text { Knowledge about } \\
\text { cognition }\end{array}$ & 15.720 & .93630 & 7.7500 & 2.50651 & 14.860 & .01 \\
\hline Regulation of cognition & 31.56 & 1.8046 & 18.00 & 4.28344 & 14.546 & .01 \\
\hline $\begin{array}{l}\text { Total of both dimensions } \\
\text { Metacognitive Awareness }\end{array}$ & 46.92 & 2.613 & 26.54 & 6.607 & 14.306 & .01 \\
\hline
\end{tabular}

The results entered in table 3 show that there was a significant difference in the academic achievement of undergraduate students with high and low scores in knowledge of cognition, 
regulation of cognition and total metacognitive awareness. This indicates that students with high scores in total dimensions of metacognitive awareness i.e. Knowledge of Cognition, Regulation of Cognition and Total Metacognitive Awareness have scored high in academic achievement.

\section{CONCLUSIONS}

The present study, which has been done on undergraduate students, investigated the relationship between students' academic achievement and metacognitive awareness, Overall, the findings revealed a significant positive relationship between student's academic performance and metacognitive awareness. However, no significant difference in metacognitive awareness among males and females undergraduate students have been found, though significant difference in the academic achievement has been found between males and females, as females showed higher academic achevement as compared to male students. Students who are highly metacognitive selfregulated are those who excel in planning, managing information, monitoring, debugging, and evaluating. It can thus be concluded that the students who use metacognitive strategies are more successful compared to the ones who do not, and teachers can play important role to develop these strategies in the students. When one student talks through a topic, he is actually describing his thinking processes to himself and to his peers. Students should identify what they know and what they do not know at the beginning of any new topics learnt and this can be done via selfasking approach at the beginning of any classes. The purpose is so that the students can make conscious decision about their role as a learner, in particular for the purpose of that specific course as well as their existing knowledge on the topic they are currently undergoing - things such as what they already know, and what they want to learn from that class.

It is important to find and understand the relationships between metacognition, and academic performance as it could be used to support training programs to teach students metacognitive skills and strategies that help improve their achievement and academic performance. Results could also be used to alter teaching techniques in universities to meet learning needs and higher order skills of students.

\section{SUGGESTIONS FOR FURTHER RESEARCH}

1. The present study was confined to Chandigarh colleges only. The study can be extended to other areas of Punjab and Haryana having similar schooling environment.

2. The present study was restricted to 100 graduate students. The findings of the study need revalidation and hence larger sample can be taken up in future research endeavours.

3. The study of the same nature can be taken for school students also.

4. A similar study at different levels can be conducted to make findings more reliable and valid.

5. A module on enhancing metacognitive skills can be planned and developed which will serve the needs of Indian adolescents better. 
6. More social and psychological variables like intelligence, learning styles, motivation can be taken up in the research designs which may possibly influence metacognitive skills among different population groups in secondary and higher education.

\section{REFERENCES}

Coutinho , Savia A. (2007). The relationship between goals, metacognition, and academic success. Educate, 7(1), 39-47. Northern Illinois University : United States of America

Das, J. P., Naglieri, J. A., and Kirby, J. R. (1994). Assessment of cognitive processes, the pass theory of intelligence. Boston, MA: Allyn and Bacon

Dunning, D., Johnson, K., Ehrlinger, J., and Kruger, J. (2003) Why people fail to recognize their own incompetence. Current Directions in Psychological Science 12, 3, 83-87.

Everson, H. T., and Tobias, S. (1998) The ability to estimate knowledge and performance in college: A metacognitive analysis. Instructional Science 26, 65-79

Flavell, J. H. (1985). Cognitive development (2nd ed.). Englewood Cliffs, NY: Prentice-Hall Inc. Karpicke , JD., Butler, AC., \& Roediger, HL. (2009). Metacognitive strategies in student learning: do students practise retrieval when they study on their own? Memory, 17(4):471-9. doi: 10.1080/09658210802647009.

Kelemen WL, Frost PJ, Weaver CA. (2000). Individual differences in metacognition: evidence against a general metacognitive ability. Memory Cognition, 28(1):92-107.

Kruger, J., and Dunning, D. (1999) Unskilled and unaware of it: How differences inrecognizing one's own incompetence lead to inflated self-assessments. Journal of Personality and Social Psychology 77, 6, 1121-1134.

McCabe J. (2011). Metacognitive awareness of learning strategies in undergraduates. Memory Cognition, 39(3), 462-76. doi: 10.3758/s13421-010-0035-2.

Metacognition: The gift that keeps giving (2014) retrieved from http://www.edutopia.org / blog/ metacognition-gift-that-keeps-giving-donna-wilson-marcus-conyers

Narang, D. \& Saini, S. (2013). Metacognition and Academic Performance of Rural Adolescents. Retrieved from www.krepublishers.com/.../S-HCS-07-3-167-13-248.

Schraw, G. \& Dennison, R. (1994). Assessing metacognitive awareness. Contemporary Educational Psychology, 19, 460-475.

Sperling, R. A., Howard, B. C., Staley, R. \& DuBois, N. (2004). Educational Research and Evaluation, 10(2), 117-139.

Swanson, H. L. (1992). The relationship between metacognition and problem solving in gifted children. Roeper Review, 15(1), 43-49.

Vadhan, V., \& Stander, P. (1994). Metacognitive ability and test performance among college students. Journal of Psychology, 128, 307-309. 